\section{Da guerra à pobreza à guerra ao crime: para além do Estado Penal}

\section{The war on poverty to the war on crime: beyond the Penal State}

HINTON, Elizabeth. From the War on Poverty to the War on Crime: the making of mass incarceration in America. Cambridge, Massachusetts, Harvard University Press, 2016. 464 páginas.

\section{Marcelo da Silveira Campos \\ (iD) http://orcid.org/0000-0002-5242-7095}

Universidade Federal da Grande Dourados (UFGD), Dourados - MS, Brasil, e Instituto Nacional de Estudos Comparados em Administração de Conflitos (INCTInEAC). E-mail: marcelocampos@ufgd.edu.br

DOI: $10.1590 / 3410102 / 2019$

Este livro de Elizabeth Hinton combina texto e contexto, ao mesmo tempo que desloca a (já antiga) discussão sobre a ascensão do Estado penal americano como decorrência do enfraquecimento do Estado de bem-estar social nos Estados Unidos. A tese da autora é provocativa: a "Guerra contra a Pobreza", um dos pilares do Welfare State daquele país, gerou uma "guerra contra o crime", na gestão do Presidente Lyndon Johnson, a partir de 1966, levando ao encarceramento massivo de jovens negros nas décadas seguintes, 1970 e 1980, superlotando os presídios americanos.

A hipótese sustentada empiricamente pela autora é clara e direta: prisóes, detençóes e as instituições da justiça criminal norte-americana operaram como uma engrenagem central na desigualdade, e, o mais importante, essa "campanha punitiva" foi iniciada no apogeu da reforma liberal e da revolução dos direitos civis (civil rights revolution), ou seja, nos anos de 1960, quando a nação estadunidense parecia pronta para abraçar políticas que realizariam plenamente seus valores fundadores igualitários.

Como contraste empírico-analítico à análise empreendida por Hinton, retomamos a tese clássica de Loïc Wacquant (2001) sobre a chamada "penalidade neoliberal", que apresenta o paradoxo de remediar um Estado "mais policial e penitenciário" com "menos Estado econômico e social", no momento em que o Estado americano (europeu, ou mesmo o caso brasileiro citado por Wacquant) torna-se incapaz de conter a decomposição do trabalho assalariado e a hipermobilidade do capital.

Para Elizabeth, esse processo, cujo ápice ocorreu nos anos de 1980 e 1990, com a Guerra às Drogas, já havia começado nos anos de 1960, quando da Guerra contra a Pobreza, que andou pari passu com a aprovação da expansão dos direitos civis (Civil Right Act), especialmente a expansão dos direitos de voto (Voting Rights Act) aos afro-americanos, que passaram a participar do pleito eleitoral em condiçóes iguais de cidadania. ${ }^{1}$ Em 1965, o Presidente Johnson declara que aquele seria o ano "em que este país começou uma guerra inteligente e eficaz contra o crime". Agora, políticos republicanos e democratas se unem para combater o crime, que, mais adiante, se tornaria a mais longa guerra contra o crime, encabeçada pelo Presidente Ronald Reagan: a Guerra às Drogas. É essa suposta "guerra inteligente e eficaz contra o crime" que acabaria por produzir a atrocidade contemporânea do encarceramento em massa. A pedra angular de Johnson foi o Safe Streets Act, de 1968, que investiu inicialmente 400 milhóes de dólares no combate ao crime. Nesse contexto, a Law Enforcement Assistance Administration (LEAA) tornou-se a agência federal com mais rápido crescimento nos anos de 1970: o Congresso havia alocado 10 milhóes de dólares, em 1965, para a guerra contra o crime; em 1973, o montante salta para cerca de 850 milhóes de dólares. Quando a LEAA foi finalmente dissolvida em 1981, durante o primeiro ano do governo Reagan, aproximadamente 10 bilhóes de dólares tinham sido destinados a cerca de 80 mil projetos voltados ao controle do crime.

\section{Demandas por direitos e processos criminalizadores: war on poverty and war on drugs}

$\mathrm{O}$ argumento de Hinton, portanto, estabelece uma conexão ímpar no bojo da complexa relação entre demandas de grupos minoritários por ampliação de direitos - o surgimento de grupos ativistas negros 
e latinos, que pediam a autodefesa, como os Panteras Negras - e o aumento do poder repressivo e criminalizador do Estado. Ou seja, houve uma espécie de resposta para a expansão da polícia, com o aumento da vigilância, especialmente em comunidades urbanas de baixa renda após 1965 . Nesse contexto, esses grupos minoritários recorreram a uma longa tradição de mobilização de ação direta contra a brutalidade policial e a aplicação da lei, que assumiria abordagens diferentes ao longo dos anos de 1970, fato esse que, evidentemente, continua até hoje.

Segundo a autora, esse processo acentua-se nos anos de 1980, quando os centros de atendimento social, estabelecidos durante a Guerra contra a Pobreza, não foram mais encontrados em nenhum dos bairros mais vulneráveis e isolados das cidades norte-americanas. Moradores não tinham mais, portanto, ninguém para chamar, mas a polícia continuava lá presente, nos bairros que careciam de reabilitação abrangente ou programas de bem-estar social. Foi assim que as instituiçóes de aplicação da lei e justiça criminal tornaram-se as últimas agências públicas em pé. Os policiais serviram como a primeira linha de contato entre os cidadãos e o sistema judiciário, o que facilitou a entrada dos cidadãos nas prisóes e o encarceramento em massa de negros e latinos. Dito em poucas palavras: essa parcialidade estatal ocultou a dimensão racista do Estado carcerário. É nesse sentido que a Guerra às Drogas deve ser considerada um componente num conjunto muito maior de políticas domésticas denominadas pelo governo estadunidense de "anticrime", mas que acabaram por focalizar principalmente a juventude negra e suas famílias.

Antes dos anos de 1980, os programas national law enforcement introduziram várias formas de vigilância nos programas de bem-estar social: rotularam grupos inteiros de americanos como prováveis criminosos, realizando operações que criaram economias subterrâneas e "combateram" gangues com forças policiais militarizadas em conjunto, com severas diretrizes de condenação nas sentenças. Em conjunto, essas práticas ajudaram a alimentar o fenômeno do encarceramento em massa, e a levar a nação para uma encruzilhada fiscal e moral. Colocando nesses termos, a autora bem aponta que as raízes do encarceramento em massa já haviam sido firmemente estabelecidas. E, certamente, este é um dos pontos fortes do livro, porque existiu, inclusive, um consenso bipartidário dos formuladores de políticas nacionais nas duas décadas anteriores à Guerra às Drogas, de Reagan, na década de 1980. O ponto central da autora é: a expansão do Estado carcerário deve ser entendida como a resposta do governo federal à transformação demográfica da nação em meados do século XX, e, especialmente, aos ganhos dos movimentos dos direitos civis afro-americanos e a ameaça de rebelião urbana. A tese da autora mostra forte relação com o filme BlacKkKlansman (Infiltrado na Klan, 2018), coescrito e dirigido por Spike Lee. Baseado no livro autobiográfico Black Klansman, de Ron Stallworth (2018), conta a história de um detetive negro, inicialmente chamado para investigar o próprio movimento negro pelos direitos civis nos Estados Unidos. No filme, Angela Davis é o alvo de suas investigaçóes, primeiro para que ele ganhasse legitimidade dentro da polícia de Colorado. Só então é que o detetive consegue seu objetivo: infiltrar-se na Ku Klux Klan.

Um segundo ponto importante na tese da autora: grande parte dos afro-americanos foram excluídos de programas como a Ajuda às Crianças Dependentes (Aid to Dependent Children) e de muitos outros programas de assistência social associados ao New Deal. O “combate” da administração Kennedy à delinquência foi uma das primeiras respostas do governo federal ao impacto da Grande Migração nas cidades americanas. Das cinzas do "motim" de Watts em agosto de 1965, houve crescente consenso entre políticos, administradores federais, funcionários responsáveis pela aplicação da lei e jornalistas, que passaram a entender o crime como algo específico da juventude urbana negra, a exemplo das rebelióes de Newark e Detroit, em julho de 1967. A administração Johnson acreditava que os homens afro-americanos abaixo de trinta anos, e influenciados por ativistas de direitos civis que advogavam cada vez mais autodeterminação e controle da comunidade, foram os principais responsáveis pelo "desassossego" nas comunidades de baixa renda. Por conseguinte, esse grupo rapidamente emergiu como principal alvo dos formuladores de políticas federais.

A doutrina liberal da década de 1960 enfatizou, consistentemente, os danos do preconceito na socie- 
dade americana. $\mathrm{O}$ ataque de Kennedy à delinquência e a Guerra contra a Pobreza, de Johnson, foram vistos pelos formuladores de políticas federais como tentativas de abordar, finalmente, a desigualdade racial que manchava a história americana. E, assim, deviam promover oportunidades para os cidadãos que foram sistematicamente excluídos da vida cívica. Ao mesmo tempo, é durante a década de 1970 que a diferenciação das técnicas de controle do crime e do criminoso na vida cotidiana dos afro-americanos de baixa renda intensificam-se conjuntamente aos programas sociais urbanos, cada vez mais integrados nas burocracias, instituiçóes e indústrias, no coração do Estado carcerário. A imposição contínua de sobreposição entre diferentes métodos de vigilância foi um processo que estimulou o historiador Heather Ann Thompson (2010) a descrever esse cenário sociopolítico como "criminalização do espaço", que desenhava e traçava dispositivos de controle e segurança na vida cotidiana dos americanos urbanos de baixa renda. Como Nixon agiu para enfraquecer os programas da Guerra contra a Pobreza, sua administração conduziu o Congresso a revisar as fórmulas de subvençóes e a financiar incentivos para refletir e redefinir suas próprias prioridades, dentre as quais a construção de novas prisóes. Embora os estados tivessem autonomia relativa em como gastariam o dinheiro designado para fins de controle do crime, houve incentivo para concessôes em bloco, visando expandir o encarceramento no início dos anos de 1970. As prioridades punitivas do consenso bipartidário incluíam a vigilância extensiva, desencadeada por agentes do FBI e da polícia local, contra militantes negros e organizaçóes civis mais à esquerda.

Com efeito, a mobilização de leis para recursos orçamentários de execução, o crescimento do sistema prisional e as altas concentraçôes de homens de baixa renda atrás das grades podem ser medidos com mais clareza no uso de discricionariedade pelas autoridades e seus financiamentos. Durante os governos de Nixon e Ford, alocaçóes discricionárias ofertaram à Casa Branca um meio de instituir iniciativas de aplicação da lei de sua própria escolha, apoiadas no extenso desdobramento de unidades policiais especiais militarizadas, no uso de vigilância eletrônica e em estratégias secretas, que muitas vezes obscureciam a distinção entre o aprisionamento e o trabalho policial. O caráter discricionário desses fundos orçamentários para melhorar a segurança em projetos de habitação pública acabou criando novas ligaçóes entre todo o espectro das agências executivas responsáveis pelos programas sociais domésticos. Todas essas medidas asseguraram que os programas da guerra contra o crime permanecessem focados em comunidades de baixa renda.

Embora os membros do amplo consenso político que mobilizou a guerra contra o crime e, mais tarde, a Guerra às Drogas tenham se diferenciado nos contornos da vigilância governamental e das liberdades civis em geral, sua determinação era policiar cidadãos urbanos pobres. Isso provou ser uma força unificadora e bastante poderosa. Nesse sentido, tanto os liberais quanto os conservadores temiam que a violência urbana coletiva se tornasse uma característica permanente na vida norte-americana. E, o mais importante, é que Hinton nos mostra que esse "consenso" político náo poderia compreender estratégias de prevenção e de controle do crime fora da criação de um papel mais central da aplicação da lei em bairros vulneráveis. Até mesmo o procurador-geral de Johnson, Ramsey Clark, considerado um dos funcionários federais mais liberais de sua época, foi responsável pela articulação do objetivo principal desse consenso político em seu depoimento durante as audiências da Câmara sobre delinquência juvenil em 1967. Para Clark, liberais e conservadores estavam aliados no Congresso para a fusão do bem-estar social com programas punitivos, com foco na juventude negra, em programas urbanos domésticos. Essa política parecia "a melhor maneira de proteger a sociedade, porque, para melhor ou para pior, essas pessoas estarão conosco, e é melhor que os endireitemos" (Hinton, p.18).

O consenso se reforçava em novas formas de compreender e responder ao crime urbano; formas essas emergidas nas décadas de 1960 e 1970 e baseadas em pesquisas sobre o crime urbano, muitas delas apoiadas por financiamento federal e fundamentadas em interpretaçóes culturais de igualdade racial. Alertando, consistentemente, a urgência de se atentar para a questão do crime, os novos dados e as novas políticas se tornariam uma força de autoperpetuação, que moldou profundamente as políticas domésticas e encorajou o fluxo contí- 
nuo de recursos de aplicação da lei em comunidades afro-americanas de baixa renda. A pesquisa do período pós-Guerra Civil prolongou uma longa tradição racial de entendimentos preconceituosos sobre o crime e o criminoso. Nas décadas seguintes à emancipação, estudiosos, formuladores de políticas e reformadores da previdência social analisaram as taxas díspares de encarceramento negro como "prova” empírica da "natureza criminosa" dos afro-americanos. O censo de 1890 e as estatísticas de prisão constituíam-se em bases para discussóes populares e acadêmicas sobre os negros americanos como uma "população perigosa". Vinte e cinco anos após a Guerra Civil e a primeira geração removida da escravidão, os números do censo indicavam que os afro-americanos representavam $12 \%$ da população do país, mas $30 \%$ de seus prisioneiros. As altas taxas de detenção e encarceramento dessa população serviram para criar o que o historiador Khalil Gibran Muhammad (2010) chamou de "discurso estatístico" sobre o crime negro na imaginação popular e política. Esses dados informaram profundamente os debates nacionais em curso sobre diferenças raciais. Como secretário assistente de trabalho durante o governo Johnson, Daniel Patrick Moynihan também promoveu a ideia de que a pobreza poderia ser aliviada com intervenções estratégicas em comunidades negras. Em março de 1965, pouco depois de Johnson iniciar a guerra contra o crime, Moynihan fez circular o memorando Família Negra. Conhecido como Relatório Moynihan, o documento argumentava que o impacto combinado de uma longa história de discriminação racial e "privação cultural" produziu um "emaranhado de patologias" em famílias e comunidades urbanas negras, evidenciado por altas taxas de analfabetismo. A administração Johnson aceitou a visão de Moynihan da patologia como a causa básica da pobreza enquanto reconhecia a pobreza como a causa raiz do crime.

Em suma, os crimes, as vítimas e os infratores são encontrados com mais frequência nas áreas mais pobres, deterioradas e socialmente desordenadas das cidades. Os dados do FBI apoiaram a percepção do governo Johnson de que "a maioria dos crimes, onde quer que sejam cometidos, são cometidos por meninos e homens jovens, e que a maioria dos crimes, por quem quer que sejam cometidos, são cometidos nas cidades" (Hinton, p.21). Os formuladores de políticas federais tinham um local específico (centros urbanos) e um grupo específico (homens jovens se aproximando da idade adulta) para aplicação da lei americana. Moynihan juntou-se aos cientistas científicos conservadores Edward Banfield e James Q. Wilson na defesa do desinvestimento de programas de ação comunitária e outras iniciativas de bem-estar social. ${ }^{2}$ À medida que as taxas de criminalidade reportada aumentavam, juntamente com o investimento do governo federal em forças policiais e programas de pesquisa, os três passaram a ver a pobreza em comunidades negras como um fato da vida e do crime nos Estados Unidos, ou seja, como algo inato aos afro-americanos. Em vez de constituir um aspecto de um programa mais amplo de reforma e elevação social, a guerra contra o crime, de Nixon, buscava oferecer, por si só, um meio de resolver (ou pelo menos administrar) os sintomas da pobreza histórica e da pobreza da população negra.

Nos anos de 1970, a prisão deliberada e encarceramento de homens jovens e afro-americanos se tornou uma estratégia para prevenir futuros crimes. Ao mesmo tempo, surgiam "novas abordagens teóricas e científicas" para a compreensão do crime e do criminoso, como a de James Wilson, que atribuiu o aumento do crime violento na década de 1960 ao fenômeno da crescente populaçáo jovem da nação americana. Wilson pediu aos decisores políticos que desenvolvessem programas de controle do crime baseados em realidades demográficas. "A única maneira segura que sabemos de combater o crime é o controle da natalidade" (Hinton, p.22), concluiu. Poderíamos lembrar ainda, no mesmo período, do economista Gary Becker, com a sua Teoria Econômica do Crime (TER). Becker (1968), ao estudar o crime, empregou o raciocínio econômico no clássico artigo "Crime and punishment: an economic approach", que marca o início dos trabalhos de uma corrente denominada "teoria econômica do crime”. A ideia central do autor é que os indivíduos contrastam os custos e benefícios esperados de suas açóes quando decidem pelas condutas conformes ou contrárias à lei, ao compará-las com os resultados do seu tempo de trabalho no mercado legal, considerando a probabilidade de 
apreensão, condenação, a severidade da punição e maior ou menor propensão do indivíduo ao "risco" de cometer um ato ilegal. A decisão de cometer um crime resultaria, portanto, da maximização da utilidade esperada, em que o indivíduo calcula os futuros ganhos da ação criminosa, o valor da punição e as probabilidades de detenção e de aprisionamento; e, por outro lado, o custo de oportunidade de cometer um crime através do salário no mercado de trabalho legal. A formulação de Becker sobre a Teoria Econômica do Crime é citada por Foucault (2008), em Nascimento da biopolítica, ao tratar da formulação teórica da racionalidade neoliberal. Embora Hinton não se remeta exatamente a Becker, mas sim ao seu parceiro Wilson, esse período certamente marca, nos Estados Unidos, o nascimento de abordagens teóricas e científicas que fundamentavam as escolhas dos legisladores pelo encarceramento massivo.

\section{Pobreza, crime e seletividade racial-penal: possibilidades analíticas}

O encarceramento massivo de negros e latinos no sistema prisional americano é um fenômeno importante da história contemporânea dos Estados Unidos. O livro de Elizabeth Hinton matiza a variável sócio-histórica com as variáveis políticas, que fizeram com que a Guerra contra a Pobreza se transformasse em um dos mecanismos centrais de operacionalização do Welfare State daquele país; ao mesmo tempo, a Guerra contra a Pobreza foi um dos principais mecanismos para o governo estadunidense operacionalizar, no interior das comunidades afro-americanas, a guerra contra o crime, levando ao encarceramento massivo de jovens negros nos anos de 1970 e 1980, superlotando os presídios americanos até a atual taxa de, aproximadamente, 670 presos por 100 mil habitantes. ${ }^{3}$

O livro, portanto, traz uma profícua e fina análise da história social americana e da luta dos movimentos sociais negros pela expansão dos direitos civis, e, especialmente, da criminalizaçáo da pobreza, mesmo no período do Welfare State. Nessa linha, seria inegável não correlacionar com o fenômeno do encarceramento massivo no Brasil contemporâneo, levando em conta que a primeira fase da era Lula-Dilma, entre 2004 e 2011, foram os anos de maior desenvolvimento econômico de nossa história mais recente, com taxa média anual de crescimento real do PIB de 4,3\%, segundo o IBGE, e taxa de desemprego decrescente de $12,4 \%$ da PEA em 2003 para 4,8\% em 2014, segundo a PME/IBGE. Ainda, da perspectiva social, os avanços foram igualmente significativos: 2003 a 2012, o índice de Gini reduziu-se 17,8\% (1,8\% ao ano, em média), enquanto a taxa de pobreza diminuiu 61,8\% (5,5\% ao ano, em média) (Carleial, 2015). Também seria impossível não assinalar que, justamente nesses anos, o encarceramento massivo no Brasil funcionou de modo crescente e expansivo.

Com vertiginoso crescimento da população carcerária desde os anos de 1990, é nos anos de 2000 que esse aumento se torna ainda mais exponencial: em 2005, havia 254.601 pessoas presas no Brasil; em 2015, esse número absoluto passou a 607.731 pessoas presas. ${ }^{4} \mathrm{O}$ crescimento da população carcerária no país foi de $161 \%$ entre 2000 e 2015 , ao passo que o crescimento demográfico foi de $20 \%$ no mesmo período. Entre 2005 e 2013, a população carcerária de delitos relacionados às drogas aumentou 345\%, saltando de 32.880 para 146.276 presos e presas por esse tipo de infração, sendo, igualmente, a grande maioria formada por jovens negros, com baixa escolaridade e com ocupaçóes relacionadas ao mercado informal de trabalho e/ou desempregados (Campos, 2015).

Em 2018, chegamos aos 800 mil presos no país. E a previsão é de 1 milhão de homens e mulheres presas até 2022. É evidente, portanto, que, mesmo em períodos substantivos de crescimento econômico e desenvolvimento social, tanto nos Estados Unidos como no Brasil, tais épocas coexistiram/coexistem com o fenômeno do encarceramento massivo. Assim, o grande mérito analítico do livro é observar que uma sociedade que declara guerra contra a pobreza desenvolve diferentes dispositivos de estigmatização, criminalização, segurança e controle em bairros periféricos, dispositivos esses que, quando acionados por uma racionalidade governamental, são fundamentais na estigmatização e criminalização, numa espécie de continuum para grande parcela da população negra das comu- 
nidades periféricas dos Estados Unidos. E, claro, também no Brasil. Isso porque, em matéria de política criminal, o novo nem sempre vem.

\section{Notas}

1 Sobre esse contexto, é imprescindível citar o texto clássico de Parsons ([1965] 1993): “Cidadania plena para um americano negro".

2 Wilson foi expoente de várias teorias neoconservadoras sobre a criminalidade nos Estados Unidos. Ver, especialmente, Wilson (1983) e Wilson e Kelling (2001).

3 Fonte: <https://sentencingproject.org/wp-content/uplo ads/2016/01/Trends-in-US-Corrections.pdf>.

4 Fonte: <http://depen.gov.br/DEPEN/depen/sisdepen/ infopen $>$.

\section{BIBLIOGRAFIA}

BECKER, G. (1968), "Crime and punishment: an economic approach". The Journal of Political Economy, 76 (2): 169-217.

BLACKKKLANSMAN [Infliltrado na Klan]. (2018), Direção de Spike Lee. Estados Unidos, Focus Pictures (128 min).

CAMPOS, M. S. (2015), Pela metade: as principais implicaçóes da nova Lei de Drogas no sistema de justiça criminal em São Paulo. Tese de doutorado em Sociologia. São Paulo, USP.

CARLEIAL, L. M. F. (2015), "Política econômica, mercado de trabalho e democracia: o segundo governo Dilma Rousseff'. Estudos Avançados, 29 (85): 201-214.

FOUCAULT, M. (2008), Nascimento da biopolitica. São Paulo, Martins Fontes.

MUHAMMAD, K. G. (2010), The condemnation of blackness: race, crime, and the making of modern urban America. Cambridge, Harvard University Press.

PARSONS, T. ([1965] 1993), "Cidadania plena para um americano negro”. Disponível em: <http://www.anpocs.org.br/portal/publicacoes/rbcs_00_22/rbcs22_03.htm>.

STALLWORTH, R. (2018), Black Klansman: a memoir. New York, Flatiron Books.

THOMPSON, H. A. (2010), "Why mass incarceration matters: rethinking crisis, decline, and transformation in postwar American history". Journal of American History, 97 (3): 703-758, 705.

WACQUANT, L. (2001), As prisóes da miséria. Rio de Janeiro, Jorge Zahar.

WILSON, J. Q. (ed.). (1983), Crime and publicy policy. San Francisco, California, Institute for Contemporary Studies.

WILSON, J. Q. \& KELLING, G. (2001), "Ventanas rotas: la policía y la seguridad en los barrios". Delito y Sociedad - Revista de Ciencias Sociales, 15/16: 67-79. 